\title{
Paget Disease and Intraductal Carcinoma of the Breast
}

National Cancer Institute

\section{Source}

National Cancer Institute. Paget Disease and Intraductal Carcinoma of the Breast. NCI

Thesaurus. Code C4019.

Paget disease of the breast associated with the presence of a usually high grade ductal carcinoma in situ in the lactiferous glands. 